\title{
Eli E. Sercarz 1934-2009
}

Eli Enoch Sercarz was born on February 14, 1934, in New York City to parents Aida Liberson and Morris Sercarz. His mother was a Yiddish teacher and his father was a radiation technologist. When Eli Sercarz was growing up in New York City, two eruptions of rheumatic fever prompted his mother to take him to the Rancho La Puerta spa in Tecate, Mexico, to recover. Eli's mother, Aida, worked as a secretary at the spa in exchange for his board. After a year, Eli Sercarz persuaded his mother to return home without him while he finished high school. He rode his motor scooter across the border each day to attend Mountain Empire Union High School in San Diego County, where he was valedictorian of his class.

He earned a degree in chemistry in what was then San Diego State College and then attended Harvard University, where he met Albert Coons, a renowned Professor of Bacteriology and Immunology, who became his mentor. Eli earned a doctorate in immunology from Harvard in 1960. He did his postgraduate research at Harvard (A.H. Coons) and the Massachusetts Institute of Technology (Salvador Luria). He was a Guggenheim Fellow in the laboratory of N.A. Mitchison at Mill Hill, 1970-1971, and in the laboratory of Pierre Golstein at Marseille-Luminy, 1977-1978. He joined the UCLA faculty in 1963. Eventually, he rose to the prestigious rank of Professor Above Scale, an honor reserved for those who have made novel and important contributions in their fields.

As he reached retirement age in 1997, he took a position at the La Jolla Institute for Allergy and Immunology, where he built a new laboratory. After five years (1997-2002), he moved his laboratory and his colleagues to the Torrey Pines Institute for Molecular Studies (TPIMS) in San Diego. He was still working on manuscripts and overseeing research at the time of his death.

The results of his pioneering investigations touched upon pivotal and fundamental issues in antigen processing and presentation, the function of immune-response genes encoded in the major histocompatibility complex, epitope competition, receptor repertoires, and immune response phenotypes. Eli introduced basic concepts and terminologies related to antigen determinants such as dominant and cryptic epitopes and determinant spreading, all of which are now standard concepts in immunology discourse. Determinant dominance describes the fact that the $\mathrm{T}$ cell or $\mathrm{B}$ cell immune response induced by immunization to a large protein molecule will tend to focus on only one or a few dominant epitopes among the potential antigenic determinants borne by the immunogenic molecule; the other, ignored determinants are cryptic. Cryptic determinants, however, can be made to become immunogenic by specific modifications to the immunogen or to the immunization procedure. Dominance and crypticity also relate to an epitope's ability to induce tolerance. He also discovered the phenomenon known as "determinant spreading," in which immune response focused on a few or a dominant determinant eventually spreads to other immune cells reactive to cryptic determinants, strengthening the immune attack and potentially making the disease more severe. These seminal contributions are applicable in vaccination, autoimmunity, and anticancer immunity to this day.

Together with his colleagues, Eli Sercarz authored over 370 publications. The ISI Web of Knowledge reports that the works of Eli Sercarz have been cited over 10,700 times. His academic honors include the Nachman International Prize in Rheumatology (1977), and the Lifetime Achievement Award given by the Keystone Symposia (2006) and by the Federation of Clinical Immunology Societies (2007). He was twice the recipient of the Guggenheim Fellowship and received the American Association of Immunologists (AAI) Excellence in Mentoring Award in 2007, a testimony to the more than 100 scientists he trained.

For Eli Sercarz, the aspects of playfulness and enjoyment were always paralleled by the intensity and effort of research. He regularly organized research meetings and journal clubs that were always accompanied with cheeses, fresh bagels or pastries, 
and sometimes wine (in the afternoon). Eli's love of dancing and travel to scientific meetings was legendary, and he maintained close contacts with colleagues around the world. A high-spirited man, Sercarz would often break into spontaneous dances, cajoling his colleagues to join in festive celebrations of one thing or another.

With his highly sympathetic and cheerful character, Eli rarely had a negative word to say about colleagues or competitors. The stimulating and nurturing atmosphere in the Sercarz group was fueled by Eli's concern for his trainees as people and as scientists, and his utter respect for the ideas of everyone in the group, from neophytes to seasoned veterans. He was also very easy to get along with and generous with his encouragement to young researchers.

He met his first wife, Renan, after graduating from high school. They divorced and he married Rabyn Blake, who would be his soul mate for the rest of his life. Rabyn passed away in 2018, and his daughter, Margo, died in 2001. Eli is survived by his son, Joel, two daughters, Lisa and Sarayana, two stepsons, Charles and Andrew Sheldon, and 14 grandchildren.

"The legacy of both his science and his person will always remain with us." 